\title{
NOTAS SOBRE EL ARMAMENTO IBERICO DE ALMEDINILLA
}

\author{
F. QUESADA SANZ \\ Universidad Autónoma Madrid
}

\section{Resumen}

En este artículo se analizan algunos aspectos del armamento ibérico de la necrópolis de Los Collados (Almedinilla) desde una perspectiva tipológica orientada a la resolución de aspectos sociales y culturales. Se enfatiza el carácter fronterizo del área de Almedinilla y el aire bastetano/contestano de su armamento, sin influencias meseteñas apreciables.

\section{Summary}

In this paper we study the Iberian wapons found in the cemetery of Los Collados (Almedinilla), using detailed typological analysis to reach social and cultural conclusions. We emphasize the implications of the probable North-South cultural and political border passing near the site, and the purely Iberian character of the panoply, which does not show noticeable influences from the inner Meseta.

\section{Introducción}

Desde que en 1867 L. Maraver publicara sucintamente los resultados de su "Expedición Arqueológica a Almedinilla", las armas de hierro por él halladas en la necrópolis que hoy conocemos como de "Los Collados" (VAQUERIZO, 1990b:64 ss.) han constituido uno de los puntos de referencia fundamentales para el estudio del armamento ibérico. La gloria y miseria posteriores de los materiales de Almedinilla derivan del mismo hecho: este yacimiento tiene el dudoso honor de ser uno de los primeros excavados con carácter "oficial" en la Península Ibérica, y el primero en Andalucía (PEREIRA, 1988:58, Cuadro 1; VICENT, 1984-85:35).

Maraver consideró todavía sus hallazgos como de época romana (MARAVER, 1867a:9, 1867b:328), y denominó las características espadas curvas de un filo como 
“espadas-machetes". Prueba del carácter todavía embrionario de los estudios, y de la falta de estructuración administrativa y legislativa en el campo de las antigüedades fue la pérdida para los nacientes Museos españoles de Arqueología de muchas armas de espléndida factura y conservación, que fueron desapareciendo a manos de compradores extranjeros para reaparecer finalmente en instituciones como el British Museum de Londres, el Pitt Rivers Museum de Oxford, o el Museo de Antigüedades Nacionales de París, donde se guardan algunas de las armas mejor conservadas que conocemos.

Simultáneamente a estos sucesos, en 1874 era descubierta en un paraje cercano a Lisboa la necrópolis de Alcacer do Sal, que, continuamente expoliada a lo largo de los años siguientes, proporcionó una importante cantidad de armas de la Segunda Edad del Hierro (CORREIA, 1925), que también se dispersaron en multitud de Museos y colecciones particulares, facilitando paradojicamente su conocimiento entre investigadores extranjeros. Pocos años después, en 1881, Rubio de la Serna hallaba otro importante conjunto de armas en la necrópolis de Cabrera de Mar (Bacelona), que publicaba en 1888 (RUBIO DE LA SERNA, 1888) con gran aparato erudito, incluyendo interesantes detalles sobre la forma en que se hallaron los objetos. El progreso en la investigación se manifiesta claramente en que esta necrópolis es ya clasificada como prerromana, e incluso como laietana (RUBIO DE LA SERNA, 1888:761 ss.).

La importancia creciente del armamento prerromano, originada en buena medida por la espectacularidad del hallado en Almedinilla, daba lugar durante estos años a los primeros estudios específicos sobre el tema, destacando el trabajo de F. FULGOSIO " Armas antiguas ofensivas de Bronce y Hierro; su estudio y comparación con las que se conservan en el Museo Arqueológico Nacional”, publicado en 1872. Dicho artículo, de sabor erudito muy propio de la época, mezca un amplio abanico de citas a fuentes literarias (Homero, Hesiodo, Plinio, Polibio, la Biblia) con ocasionales referencias a las armas conservadas, casi siempre procedentes de Almedinilla. Realiza Fulgosio algunas observaciones atinadas, y en su trabajo encontramos impreso por vez primera (FULGOSIO, 1872:369) el término falcata para describir los "sables" o "espadas-machete" de Maraver. Se trata de una voz creada por los eruditos decimonónicos a partir del término falx, pero inexistente en las fuentes grecolatinas, que denominan machaira $\mathrm{o}$ kopis a este tipo de espada. Del mismo modo, identifica Fulgosio -como ya lo había hecho Maraverun arma de Almedinilla con el soliferreum de las fuentes antiguas.

A finales del s. XIX las armas peninsulares comienzan a ser conocidas entre los investigadores europeos, merced a trabajos como el libro de E. CARTAILHAC Les áges préhistoriques de l'Éspagne et du Portugal, publicado en París en 1886, que recoge ya distintas armas (espadas y puñales de antenas, lanzas, falcatas) procedentes en su mayoría de los yacimientos que venimos citando: Almedinilla y Alcacer do Sal. Cartailhac aventura una fecha del s. V a. C. en adelante para este armamento, y se detiene con interés en "ciertos sables de hoja curva, ondulada, de un sólo filo" (CARTAILHAC, 1886:250). Por vez primera se compara el tipo hispano con posibles paralelos mediterrá- 
neos, ilustrando paralelos de la falcata en cerámicas de Figuras Rojas halladas en Italia, en una estela de Volterra, e incluso presentando armas similares de Grecia y de Italia.

No es hasta principios del siglo XX cuando se producen avances significativos en el estudio del armamento ibérico, por fin identificado como tal. Uno de los principales responsables es P. París, quien además de importantes excavaciones -entre ellas, nuevos trabajos en Almedinilla (QUESADA Y VAQUERIZO, 1990:16)- publicó una larga serie de trabajos de indudable importancia para el conocimiento de la cultura ibérica en general. En este contexto, y en un ambiente científico en el que una falcata podía figurar todavía como "sable sarraceno" en las colecciones del Museo de Artillería de París (PARIS, 1904:277 n.2), P. Paris presentó una tipología embrionaria de armas ibéricas en la que recogía las ideas de Cartailhac sobre el origen griego del sable curvo de un filo. Igualmente aludió a la inutilización de las armas por doblado, a la rica decoración damasquinada, etc. aunque su interés por los paralelos micénicos le llevó a comparar la decoración de una de las falcatas de Almedinilla con los puñales egeos (1904:282).

Aunque a partir de entonces los nuevos hallazgos -en especial los realizados en la Meseta por el Marqués de Cerralbo- disminuyeron el protagonismo del armamento de Almedinilla, la excepcional conservación y calidad de algunos de sus ejemplares permitió que durante muchos años las armas de esta localidad, sobre todo sus falcatas, conservaran un peso importante en las publicaciones dedicadas a la panoplia de la Segunda Edad del Hierro, como las de SANDARS (1913), o M.E. CABRE (1934a, 1934b).

Sin embargo, las armas de Almedinilla, pese a lo lejano de su descubrimiento, no fueron publicadas en conjunto hasta fechas mucho más recientes, en concreto hasta 1969 , año en que W. SCHULE recogí el que todavía sigue siendo mayor repertorio de dibujos sobre ellas (SCHULE, 1969: Láms. 72-81). Con todo, el catálogo publicado más completo es el aún más reciente de VAQUERIZO (1989), que recoge de manera sistemática los materiales hoy conservados en diversos museos, proporcionando sus dimensiones y cotejando además la información con las antiguas notas de Maraver. Dicho trabajo nos exime de detallar las características de las armas, para centrarnos en otras cuestiones no abordadas por Vaquerizo. En todo caso, debe recordarse que la ausencia de contextos cerrados -ajuares de tumbas- limita bastante el tipo de preguntas con criterios actuales que pueden realizarse a estos materiales (VAQUERIZO, 1989:225226). Con todo, es posible realizar algunas consideraciones de cierto alcance.

\section{Armamento, fronteras y geografia}

La necrópolis de Los Collados en Almedinilla forma parte de una cadena de yacimientos ibéricos, orientada en dirección N-S, que delimita un área (a grandes rasgos la Alta Andalucía) en la que abundan las armas de hierro ibéricas, y que separa dicha región de la Baja Andalucía, donde el armamento en hierro es casi inexistente.

La FIG. 1 refleja gráficamente esta situación: los puntos indican los yacimientos 
andaluces (necrópolis en casi todos los casos) en los que se ha documentado armamento de hierro. Se aprecia claramente una "frontera" en una línea que parte de Sierra Morena (Collado de los Jardines), llega al Guadalquivir en la zona de Cástulo y desciende hasta el Genil pasando por Porcuna-Martos-La Bobadilla-Fuente Tojar-Almedinilla-Iznájar. Al Este de dicha línea el armamento abunda en yacimientos como Toya, Baza, Mirador de Rolando, Illora, Galera, Moraleda de Zafayona, etc. Al Oeste de dicha "frontera" armamentística sólo ocasionalmente se documentan armas de hierro, normalmente aisladas y de contextos a veces dudosos (Arcos de la Frontera, Prado de San Sebastián, La Rinconada, Almodóvar del Río). Además, es más que probable que todas estas armas se daten en época tardía, a partir de la Segunda Guerra Púnica como muy pronto.

En realidad, la línea que hemos citado no marca sólo una distinción entre la aparición de armas de hierro y su ausencia, sino que en realidad responde a la línea existente entre una zona (Alta Andalucía) donde sabemos de la existencia de numerosas necrópolis ibéricas (PEREIRA, 1989) y otra en la que dichas necrópolis brillan por su ausencia (ver al respecto, entre una creciente bibliografía, ESCACENA, 1987:295 s.s.; 1989:465 ss.; 1990 e.p., con una polémica interpretación sobre las causas de dicha ausencia).

Si ponemos en relación no solamente la presencia/ausencia de necropolis y armamento, sino también otros elementos arqueológicos, como la presencia de cajas funerarias (ALMAGRO GORBEA, 1982) veremos que todos ellos tienden a definir un límite bastante preciso entre lo que tradicionalmente se entiende como Bastetania y Turdetania, sin entrar por ahora en la adscripción concreta de la zona de Cástulo, al Norte. La zona de Almedinilla, a nuestro juicio, quedaría claramente englobada en el área bastetana, aunque algunos de sus elementos de cultura material tengan rasgos propios de la zona del Genil e incluso del área sevillana, en especial durante el s. II a.C., como muestra el yacimiento del Cerro de la Cruz, vecino a la necrópolis de Los Collados (QUESADA, VAQUERIZO, MURILLO, 1992 e.p.). Sin embargo, la presencia de algunos materiales "mixtos" no contrapesa la nítida barrera existente en cuestiones como necrópolis o armas, de modo que quizá la delimitación en el área de la Subbética fuera más nítida de lo que algunos autores han opinado recientemente (PASTOR, CARRASCO, PACHON, 1990 e.p.), aunque es cierto que otros elementos presentan problemas, en especial la escultura andaluza del "grupo antiguo" (CHAPA, 1986 con completa bibliografía; también RUANO, 1983) que aparece a caballo de ambas zonas, aunque se limite mucho en el corazón de la Bastetania.

En otro sentido más preciso se aprecia también una diferencia entre las áreas al Este y Oeste de la línea Linares-Almedinilla-Iznájar. Antes hemos enfatizado la ausencia de armamento de hierro al Oeste de la misma, pero ello no quiere decir que, al menos en momentos antiguos de la Edad del Hierro, no se haya documentado tipo alguno de arma en la Baja Andalucía. Bien al contrario, es en dicha zona donde aparece el mayor número de puntas de flecha de anzuelo en bronce, además de otras variantes (QUESADA, 1989a, con la bibliografía pertinente). 
Aunque todavía no está clara la pervivencia que este modelo de puntas de tipología “fenicio-púnica" -típico de los ss. VII-VI a.C- pudo tener en los ss. V-II a.C. (QUESADA, 1989a:169), no puede ser casualidad la distribución que ofrecemos en la FIG. 2. En ella se compara la distribución conocida de las falcatas ibéricas (ss.IV-I a.C.) con la de las puntas de flecha de doble filo y anzuelo (la más frecuente de entre las puntas broncíneas). Aunque es probable que en conjunto las puntas sean más antiguas que las falcatas, -lo que tampoco es seguro, a falta de contextos precisos para casi el $100 \%$ de las puntas de anzuelo-, no cabe duda que la distribución de las primeras es casi un negativo de la de las segundas. No deja de ser significativo que la línea " fronteriza" entre ambos tipos de arma sea a grandes rasgos la misma que hemos visto en la FIG. 1. Ś́lo en Cástulo -que parece haber tenido un carácter especialmente cosmopolita como "port of trade" terrestre (DOMINGUEZ MONEDERO, 1988)- conviven un número apreciable de puntas de bronce y armas ibéricas de hierro, fenómeno que sólo se reproduce en dos yacimientos "mixtos" como Villaricos y Peña Negra de Crevillente.

Aparte de estas implicaciones de medio alcance sobre el carácter fronterizo de la zona de Almedinilla, no cabe duda que este fenómeno puede tener un alcance mayor si consideramos estas puntas como arma característica de un mundo punicizante predominante en la Baja Andalucía frente a las armas empuñadas de hierro típicas del ámbito ibérico, lo que coincide con hipótesis recientes sobre el fuerte componente púnico del ambiente turdetano, (p. ej. BENDALA, 1987:141 s.s.; 1989:142-143). Dicha hipótesis debe resolver, sin embargo, la cuestión de la perduración o no de estas puntas de flecha en el Bajo Guadalquivir y Genil durante los ss. IV-III toda vez que parece demostrado que en el Sureste estas puntas rara vez llegan a contextos de principios del s. IV, datándose sobre todo en los ss. VI-V a.C. (QUESADA, 1989a).

Dicho todo esto, podemos considerar que el armamento de Almedinilla se integra claramente dentro del conjunto del armamento ibérico bastetano, que aparece en un yacimiento limítrofe con una zona culturalmente distinta, que podríamos en algún sentido considerar como "fronterizo", aunque de ello no se deduzca necesariamente que la abundancia de armas tenga que ver con la ubicación geográfica del yacimiento. Nótese sin embargo que el criterio armamentístico no es en sí causa suficiente para proponer una "frontera", sino que debe combinarse con una amplia serie de datos mucho más significativos, toda vez que los patrones de difusión de la tecnología armamentística tienen rasgos peculiares que facilitan una rápida expansión y amplia permeabilidad (QUESADA, 1989b).

\section{Falcatas}

Procedentes con bastante seguridad de Almedinilla (sobre la problemática de adscripción de algunas piezas, VAQUERIZO 1989) conocemos un total de 53 espadas y puñales, distribuidos del modo siguiente: cinco falcatas de cabeza de ave, cinco de cabeza de 
caballo, treinta y cuatro con la empuñadura total o parcialmente perdida, dos espadas de frontón, dos espadas cortas o puñales de empuñadura de frontón, dos puñales de hoja triangular con base ancha, una espada corta de empuñadura facetada, de tipo "Alcacer do Sal", dos fragmentos de espada corta o puñal (FIG. 3).

Este conjunto, en el que predomina de modo absoluto la falcata como tipo característico de espada, es plenamente ibérico en composicion y proporciones. Si comparamos los datos de Almedinilla con los de otros yacimientos con un número estadísticamente significativo de espadas, hallaremos que los porcentajes son similares. Así se refleja en la FIG. 4, que compara los datos de Almedinilla con otros de Baza (Granada), Cabecico del Tesoro y Cigarralejo (Murcia). En todos los casos las proporciones son casi idénticas. La única anomalía corresponde a la elevada proporción de falcatas del Cigarralejo cuya empuñadura es reconocible, debido a la meticulosa excavación del Dr. Cuadrado.

Las falcatas de Almedinilla se caracterizan por lo general por su buena conservación, apreciable sobre todo en los ejemplares del British Museum (FIG. 5), pero tipológicamente entran dentro de los parámetros habituales del cuadrante Suroriental de la Península Ibérica. La falta de contexto impide precisar sobre bases sólidas la coexistencia o no en el tiempo de empuñaduras con cabeza de ave y caballo, de acanladuras divergentes o paralelas, etc. (QUESADA, 1988,en especial pp. 294 ss.). Con todo, sí hay un rasgo diferenciador entre las armas de la zona cordobesa y las del ámbito murciano y alicantino, aunque tal diferencia no es apreciable en ejemplares individuales, sino sólo en conjuntos amplios: las falcatas de la Alta Andalucía -y en especial las de Almedinillason por lo general considerablemente más cortas que las murcianas y alicantinas, y el resto de las dimensiones -salvo la longitud de las empuñaduras, que es constante por evidente necesidad- disminuye proporcionalmente.

La dimensión más útil para trabajar no es la longitud total, sino la de la hoja solamente (QUESADA, 1989c: vol. I, 236 ss.; 1991:311), y ella nos permite expresar la diferencia de modo claro: la longitud media de la hoja de un total de 228 falcatas ibéricas con hoja completa es de $48.8 \mathrm{~cm}$., pero la media de la región de Murcia-Albacete es de $50.9 \mathrm{~cm}$. (por encima), mientras que la de las falcatas de la Alta Andalucía apenas alcanza los 45.9 $\mathrm{cm}$. Una diferencia de magnitud del orden del $10 \%$ en la longitud, acompañada de la dismi-nución correspondiente de anchura y peso, es en sí importante. Aún más claro resulta otro dato: mientras que en Murcia-Albacete un $61 \%$ de las falcatas tiene hojas mayores de $48 \mathrm{~cm}$., en Andalucía sólo un 30\% de las hojas supera esa dimensión. Parece pues que unas pocas piezas, quizá incluso importaciones del Sureste, no alcanzan a oscurecer el menor tamaño de las falcatas andaluzas, y en especial las de Almedinilla. Esto puede derivar de una penetración de la falcata hacia el interior más tardía que la original adaptación costera (¿alicantina?) del tipo a partir de prototipos itálicos mucho mayores que alcanzan hasta un metro de longitud (QUESADA, 1990a:80.81). De hecho, las escasas falcatas halladas en el interior de la Meseta (p. ej. Gormaz, La Osera) tienden a ser aún menores que las andaluzas, llegando a los valores más bajos de toda la Península. 
Los elementos de vaina conservados muestran una tipología plenamente coherente con la habitual del mundo ibérico, espléndidamente estudiada por CUADRADO (1989:22 ss.), con fundas de cuero, abrazaderas de hierro, anillas de suspensión y ocasionalmente cantoneras metálicas para dar mayor rigidez al conjunto. No hay ningún rastro de unas -por otro lado inexistentes- vainas metálicas enterizas de falcata, pese a lo que algún autor ha propuesto recientemente.

Un rasgo tradicionalmente bien estudiado de las falcatas de Almedinilla es la decoración damasquinada en plata de algunas de ellas (CABRE, 1934a. 1934b, NIETO Y ESCALERA, 1970). En total, conocemos damasquinados en siete falcatas de Almedinilla (Córdoba 62, 1958, 1059, 1068, MAN 10475, 10480, 10481) lo que supone un $16 \%$ de las falcatas, la cifra más elevada en absoluto y en proporción de cualquier yacimiento ibérico (QUESADA, 1990b:50). En realidad, sospechamos que buena parte de los damasquinados de muchas falcatas se han perdido por la acción del tiempo y la corrosión, y creemos que otras muchas decoraciones permanecen todavía debajo de espesas capas de oxido y tierra en las muchísimas falcatas que duermen sin restaurar en los Museos (sobre todo después del descubrimiento del ave damasquinada en la hoja de la falcata 10475 de Almedinilla, NIETO Y ESCALERA, 1970). Pero en todo caso, la elevada proporción relativa de damasquinados en las falcatas de Almedinilla debe movernos a reflexión, sobre todo si atendemos a la presencia de damasquinados en otras armas de la zona (puñales, lanzas) y a la propia dispersión conocida de damasquinados en falcatas (QUESADA, 1990b:45).

Algunas de las decoraciones, de fuerte influencia mediterránea, son bien conocidas desde antiguo, mientras que otras han pasado inadvertidas hasta hoy, como la cabeza de lobo damasquinada sobre la hoja de Córdoba 62 (QUESADA, 1990:56, e.p. Lám. 41), que, mirando hacia la punta desde el extremo de las acanaladuras, quizá tuviera un valor protector o quizá incluso un significado de agresividad. En todo caso, no cabe duda de que la zona de Almedinilla-Illora-Ceal fue uno de los principales centros productores de espadas damasquinadas (a no ser que queramos mirar un poco más al norte, hacia Cástulo, que sería una buena sede para una industria tan especializada y preciosista como esta). En todo caso, la pieza de mejor calidad que conocemos, sin duda alguna, no es la de Almedinilla, sino la menos conocida de Illora (QUESADA, 1990b: 53 y 58), localidad por lo demás cercana a la propia Almedinilla.

Por último, resulta conveniente señalar que, aunque en la actualidad se expongan enderezadas, la mayoría de las falcatas de Almedinilla fueron halladas dobladas sobre sí misma, a menudo con varias curvas (VAQUERIZO, 1989: Lám. 1). al menos 14 falcatas estaban dobladas frente a 10 que no lo estuvieron; el resto es indeterminable. El que fuera posible enderezarlas -con más que discutible criterio museográfico- prueba más que nada el excelente estado de conservación de las piezas. Prueba del a nuestro juicio indudable carácter ritual y simbólico del acto de inutilización (QUESADA, 1989c:i, pp. 223-231) es que en muchos casos, además, se golpeó el filo y el dorso de la falcata contra un objeto 
duro, posiblemente una piedra, mellando intencionalmente el filo. Puesto que las melladuras no corresponden a golpes contra otra espada o un escudo -por su morfología, y puesto que inutilizar el filo de las armas no ayuda a encajarlas dentro de una cista o urna, parece claro que esta actuación tiene por objeto inutilizar el arma tanto en el plano práctico como en el simbólico. Dicho fenómeno fue apreciado en su momento por NIETO y ESCALERA (1970:28-29) y posteriormente valorado en su contexto simbólico por E. Cuadrado en el Cigarralejo (CUADRADO, 1981:62) y por nosotros mismo en el Cabecico del Tesoro (QUESADA, 1989c, I, 230, II, Lám. LXXI). En Almedinilla conservan evidencias indudables de mellado 8 falcatas, frente a 3 que no lo están. El resto es indeterminable.

\section{Espadas rectas y puñales}

En el mundo ibérico del Sureste y Alta Andalucía los diversos tipos de espada recta suman siempre una proporción muy baja en relación con las falcatas, al igual que los puñales. Ciñéndonos al caso de Almedinillla, vemos que los dos ejemplares de espada corresponden al tipo de empuñadura de frontón de una variante característica del Sureste (Casa del Monte, Hoya de Santa Ana, Los Nietos, Villaricos) aunque el tipo está ausente en yacimientos como Cabecico y Cigarralejo. Se trata (QUESADA, 1991:549-587, catálogo p. 3798) de hojas de ancha hoja de perfil muy ligeramente pistiliforme y empuñadura de ancha espiga plana rematada originalmente en frontón. La guarda tiene un elemento decorativo en forma de palmeta estilizada, proyectado por encima de las cachas, que también aparece en alguna falcata (Villaricos, Mirador de Rolando, quizá Almedinilla). A nuestro juicio este tipo de espadas, de clara raigambre mediterránea y en absoluto meseteña, tipo que aparecí sobre todo en el Sureste aunque enseguida penetró hacia la Meseta Oriental (Alpanseque, Aguilar de Anguita), corresponde a la fase más antigua de la panoplia ibérica, y desde el segundo cuarto del s. IV a.C. tendió a desaparecer, superado por la falcata que desde entonces se convirtió en la espada "bastetano-contestana" por excelencia. Aunque en Almedinilla carecemos de dataciones precisas e incluso de contextos cerrados, creemos que estas espadas corresponden a la fase más antigua de la necrópolis, quizá dentro ya del s. IV a.C.

En cuanto a la existencia de una espada recta de tipo de La Tène, citada por Maraver y luego por SANDARS (1913) y STARY (1982) no ha podido ser localizada (sobre el tema, VAQUERIZO, 1989:227-228). En todo caso, la presencia de espadas rectas de La Tène II o incluso de La Tène I no sería rara, puesto que dichas armas se dan en el Sureste desde el s. IV (QUESADA, 1990b:231 ss.) e incluso hemos identificado algunos fragmentos procedentes de la Alta Andalucía (Galera, Ceal). No creemos en todo caso (Contra Stary) que dichas espadas sean -sobre todo en La Tène Ipenetraciones desde la Meseta, sino desde la costa del Sureste (QUESADA, 1990b, 1991:720 ss., 739-740). 
Quizá los dos rasgos más característicamente "andaluces" o incluso "granadinos" de la panoplia de Almedinilla sean los que aparecen en sus puñales y en un fragmento de espada corta. Nos referimos por un lado a la presencia de empuñaduras facetadas y habitualmente damasquinadas que se suelen asociar al tipo engañosamente llamado "Alcacer do Sal", pero que aparecen a menudo en la Alta Andalucía en puñales y espadas cortas (Almedinilla, Illora, Cerro de la Mora, Baza) e incluso en el Sureste (Cigarralejo). En segundo lugar, y con mayor énfasis, insistimos en el carácter suroriental en sentido lato de los puñales cuya corta hoja triangular, de ancha base y filos rectos, conforma un tipo característico (nuestro Tipo II, QUESADA, 1991:780 ss., catálogo en pp. 3809 ss.). Los ejemplares se concentran en las zonas montañosas de la Alta Andalucía: Almedinilla (dos piezas), Illora (una) Baza (una), Castellones de Ceal (una), y en el Sureste (Cigarralejo, Calasparra, Los Nietos). S6́lo hay dos ejemplares similares en la Meseta, uno hallado sin contexto en Coca y otro del poblado de Las Cogotas, pero con detalles diferentes en la empuñadura.

La escasez de puñales en las necropolis ibéricas se debe a nuestro juicio, sin duda, a que no se trata de armas concebidas como instrumentos de guerra, sino como símbolos de estatus. En especial el tipo triangular es demasiado ancho como para ser una eficiente arma punzante, y demasiado breve de filo para ser un arma cortante. En cambio, es una pieza espectacular colocada al cinto, sobre todo si -como ocurre a menudo- el puño o incluso la hoja se decoran con plata, cobre y estaño (p. ej. HARRISON, 1980, puñal de tipo II procedente de la Alta Andalucía). No es casualidad que estos puñales, cuando se conoce su contexto, suelan aparecer en tumbas especialmente ricas (QUESADA, 1991:833 ss.). El puñal es un arma que puede llevarse envainada en momentos de paz y en actos públicos (asambleas por ejemplo) sin resultar molesto y sin resultar amenazante, pero al tiempo concentrando en sí las connotaciones de prestigio y poder que tienen los demás elementos de la panoplia. Desde un punto de vista práctico es además un arma redundante, incluso superflua si el guerrero cuenta ya con lanza/s y espada, de modo que no es rara su escasez comparativa.

Creemos por último necesario insistir en que -por distribución y cronología-, no puede sostenerse ya la hipótesis tradicional, resumida recientemente por VAQUERIZO (1989:246, 1990), que atribuía un carácter "'meseteño" a estas armas. Las que acabamos de recoger (y no nos estamos refiriendo a otros tipos de frontón tardíos o de antenas atrofiadas de la Meseta Oriental) son armas plenamente ibéricas de una fase antigua, algunas de las cuales llegaron a la Meseta, donde con el tiempo sufrieron transformaciones que las convertirían en tipos sustancialmente distintos. Las "antenas atrofiadas" de algunas armas cordobesas responden a una influencia general de origen aquitano-languedociense recibida por la Península Ibérica durante los siglos VI-V a.C., que origino "tipos" diferentes en regiones distintas. El carácter dinámico y expansionista de la metalurgia militar ibérica aparece cada vez más claro, incluso para autores bien poco sospechosos de un "iberismo exaltado", como M.E. CABRE (1990:223-224). 


\section{Lanzas}

Conocemos al menos 54 puntas de lanza y 30 regatones clasificados en diferentes museos como procedentes de Almedinilla, de modo que sobra alguna punta y falta algún regatón con respecto a los inventariados por Maraver (ver VAQUERIZO, 1989:227-229).

Las lanzas de Almedinilla forman un conjunto muy heterogéneo de formas y tamaños. La ausencia de publicaciones específicas sobre las lanzas de la Edad del Hierro dificulta realizar precisiones, pero aún así es posible realizar algunas observaciones sin entrar en un menudo análisis estadístico que, aunque ya realizado, no nos interesa ahora.

La longitud media de las puntas es de $37,44 \mathrm{~cm}$., pero dicho estadístico es muy poco significativo, dada una Desviación Estándar de 11,3. La razón estriba, claro está, en que el Recorrido es muy amplio, ya que la punta menor mide sólo $15,9 \mathrm{~cm}$., mientras que la más larga alcanza los $57,5 \mathrm{~cm}$. Resulta imposible clasificar las lanzas de acuerdo con su tamaño como en su momento hicieron Maraver y Sandars (ver detalles en VAQUERIZO, 1989:249). La razón es que si colocamos una al lado de otra, por orden descendente, las lanzas completas (FIG. 6) no hay forma de establecer una barrera o hiato entre lanzas “"grandes", “medianas" y “pequeñas". Bien al contrario, el descenso es gradual y suave, sin que además las formas de las puntas varien de acuerdo con los tamaños. Este resultado no es aislado, sino que coincide con el de los demás yacimientos que contienen un gran número de armas (Cigarralejo, Alcacer do Sal, Mirador de Rolando, Miraveche, Monte Bernorio...) (QUESADA, 1991:969 ss.). Entre otras cosas, dicho resultado implica una producción artesanal poco estandarizada (como la que se produce en el caso de las falcatas), pero sobre todo dificulta la interpretación tradicional que atribuía a los guerreros ibéricos dos lanzas, una “de tipo grande, empuñada" y otra “'de tipo pequeño, arrojadiza”' (sostenida por nosotros mismos, QUESADA, 1989c:I,283 ss., y II, 37-43 y luego matizada, QUESADA, 1991:1120-1123). En realidad, es imposible -salvo en tipos muy claros y concretos- distinguir una lanza específicamente arrojadiza de otra específicamente empuñada (QUESADA, 1989c:I, 304-307). S6́lo si disponemos de pares de lanzas de tamaños marcadamente distintos en contextos cerrados podrá sostenerse una interpretación así, y dichos contextos están ausentes en Almedinilla.

$\mathrm{Si}$ los tamaños no nos permiten distinguir tipos, deberemos acudir a otros detalles morfológicos. La sección del nervio de la lanza es un criterio engañoso: creemos que la distinción entre nervio redondo y cuadrado propuesta por algunos autores (Cuadrado, Schule) no es válida porque depende a menudo del punto en que tomemos la sección y de la dirección de los golpes del herrero (QUESADA, 1989c:I,297;1991:969-974). En cambio, sí son característicos los nervios de sección romboidal, con aristas vivas. Dichas secciones son características del mundo meseteño por oposición a los gruesos nervios redondos, cuadrados o facetados irregulares del mundo ibérico (QUESADA, 1991:1023 ss.), y están casi ausentes en Almedinilla, aunque se dan en algún ejemplar aislado (nuestros núm. cat. 950, 955, 926). En Almedinilla, y sobre todo en lanzas de hoja 
estrecha y larga, predominan los nervios gruesos, sólidos, especialmente aptos para lanzas empuñadas.

Se da también en Almedinilla un cierto número de secciones sin nervio, lenticulares o romboidales aplanadas, generalmente asociadas a puntas de tamaño mediano o pequeño (siempre menor de $35 \mathrm{~cm}$.) y que aparecen sobre todo en la Meseta -aunque no exclusivamente-, extendiéndose a toda la Península en periodos avanzados de la Cultura Ibérica, y que son especialmente abundantes en el s. II a.C., aunque tal conclusión no tiene el carácter de "ciencia exacta" (QUESADA, 1991: 1029-1031). En concreto hay algunas piezas (nuestro núm. cat. 956 por ejemplo) que son a nuestro juicio datables en el s. II a.C.

En Almedinilla faltan por completo las lanzas de hoja ondulada o "flameante" (nuestro tipo 7/forma IV) y las de ancha base semicircular (nuestro tipo 4/Forma IIC), modelos ambos típicamente célticos, que sólo se extienden por Cataluña y Meseta Norte.

La mayoría de las puntas pertenecen al tipo denominado habitualmente -y creemos que con muy poca fortuna- como "Alcacer do Sal", con hojas comparativamente estrechas y alargadas. Sin embargo, dentro de este tipo general, faltan por completo las formas más antiguas (nuestro tipo 1, forma IA) de hoja muy estrecha, filos rectos casi paralelos, gran longitud (más de $40 \mathrm{~cm}$.), y sobre todo anchura máxima en la base de la hoja, que arranca perpendicular al nervio. Dicho tipo, característico de las necropolis más antiguas tanto en el Sureste (El Molar) como en Levante (Solivella, Bovalar) o Meseta Oriental (Prados Redondos) comenzó a ser sustituido a principios del s. IV a.C. por variantes de perfil más suave y curvilíneo, muy frecuentes en Almedinilla, Alcacer do Sal y Cigarralejo, por citar ejemplos distantes entre sí. Es un modelo característico del s. IV, aunque perdura durante el s. III a.C., sin que parezca llegar al s. II.

Aunque en Almedinilla predominen las lanzas de cubo corto y hoja estrecha con grueso nervio, especialmente aptas como armas para el cuerpo a cuerpo a lo sumo para arrojarlas a pocos metros, algunas de las piezas menores son de uso claramente mixto. Además, hay al menos dos ejemplares de verutum ofalarica, piezas macizas, sin hoja, con sección cuadrada en la punta y cubo redondo, similares a algunos ejemplares murcianos (QUESADA, 1989C:I,296-297 para el término falarica erróneamente aplicado a veces a las grandes lanzas; 1989c:II, 138, 144, 148 para paralelos). No se trata de regatones largos, sino de puntas pesadas, macizas, arrojadizas, similares en aspecto al verutum latino, $\mathrm{y}$ de función similar a la del pilum romano. Aunque habitualmente estas piezas son tardías (posteriores al s. III a.C.), conocemos algún ejemplo más antiguo, de modo que no es posible avanzar una fecha para las cordobesas.

Por último, hay en Almedinilla un ejemplar de pilum (Mus. Arq. de Córdoba, n. inv. 87) con cubo y astil férreo mucho más largo que su punta corta ancha y sin nervio. Estas últimas características podrían indicar una fecha avanzada, pero tal generalización es engañosa, porque el ejemplar de pilum más antiguo de la Península, procedente de Perelada y datado en el s. V a.C. si no antes, es de forma similar. El pilum cordobés pertenece a nuestro tipo II, variante pequeña (QUESADA, 1991:900). 
Los regatones de Almedinilla son por lo general medianos y cortos, faltando los largísimos regatones típicos del s. V a.C. Por lo demás, no presentan rasgos excesivamente característicos. No hay ningún regatón céltico con vástago afilado interior (QUESADA, 1991:1104-1106).

\section{Soliferrea}

Una de las armas más características del conjunto de Almedinilla son los soliferrea, de los que no se conservan todos los ejemplares hallados (VAQUERIZO, 1989:229). Los ejemplares cordobeses depositados en el Museo de Córdoba son de dimensiones y peso normales (en torno a dos metros de longitud y 800 gr. de peso) y aparecieron doblados, aunque sufrieron el mismo proceso de "enderezamiento museologico" que muchas falcatas. Desde un punto de vista tipológico, lo más notable de las piezas de Almedinilla es su variedad formal, manifestada sobre todo en la complejidad de las empuñaduras, excepcionalmente bien conservadas. No nos cabe duda de que los soliferrea son de origen norpirenaico, desde donde entraron en la Península durante las últimas décadas del s. VI a.C. (QUESADA, 1991:848 ss.), llegando a Alicante en la primera mitad del s. V (Cabezo Lucero). En el s. IV aparecen extendidos por toda la $\mathrm{P}$. Ibérica, mientras que tienden a desaparecer en Aquitania-Languedoc, donde habían sido habituales en el s. VI a.C.

Aunque a principios de siglo se creyo (AGUILERA Y GAMBOA, 1916:37-38) que los soliferrea de Aguilar de Anguita eran más antiguos que los de Almedinilla o AvezacPrat, por su mayor simplicidad formal, según el criterio de que el refinamiento sería indicio de modernidad, los datos actuales no permiten sostener esta hipótesis. Los ejemplares norpirenaicos, los más antiguos, son a menudo los que tienen una estructura de empuñadura más compleja. Es probable que la variedad tipológica, en cuanto a la riqueza de detalles y cuidado de elaboración, se deba a facies regionales más que a cronología. Los ejemplares meseteños por ejemplo, tanto los antiguos de Aguilar de Anguita como los tardíos de la necrópolis del Raso de Candeleda, son en general más simples que los andaluces o aquitanos. En Almedinilla, en cambio, encontramos toda la variedad, desde puntas cónicas macizas hasta otras barbadas de aletas, y desde empuñaduras realizadas simplemente regruesando el centro, hasta otras complejas con molduras que enmarcan un adelgazamiento central (SCHULE, 1969:Lám. 79), similares a las características del mundo languedociense. Hoy por hoy no es posible precisar tipológicamente la datación de las piezas de Almedinilla, que podría ir en teoría del s. V a.C. al I a.C.

\section{Armas defensivas}

El armamento defensivo está representado en Almedinilla sólo por los restos de 1 umbo (no citado por Maraver), y de 22 manillas de escudo (según MARAVER, 1867b:324), de las que hoy se conservan numerosos fragmentos correspondientes al 
menos a 11 manillas diferentes. La proporción de manillas de escudo a armas ofensivas, pese a lo que pudiera parecer, es bastante elevada, teniendo en cuenta además la inherente fragilidad de las delgadas láminas metálicas que forman las manillas.

No es posible reconocer los tipos precisos de manilla a partir de los fragmentos conservados, pero con los restos disponibles sí se puede concluir que se trata en todos los casos de manillas de aletas triangulares características del cuadrante suroriental de la Península Ibérica (QUESADA, 1991:1235, tipo 3) y ocasionalmente de manillas cortas sin aletas de tipo antiguo (nuestros tipos 1 y 2). En ningún caso se dan los tipos característicamente meseteños de cinta (nuestro tipo 4) o de manilla calada (nuestro tipo 5). Por tanto, podemos hallar paralelos cercanos publicados de las manillas entre el abundante material del Cigarralejo (CUADRADO, 1989:91 ss.), como ya hizo en su momento Vaquerizo (1989:253-254). No es posible discernir el tamaño de las piezas con los restos conservados, pero algunas debieron ser bastante grandes. Tampoco aportan información cronológica, salvo algún fragmento de puño corto con aletas apenas desarrolladas y sin gusanillo, correspondiente a tipos antiguos, que se dan entre el s. V y primer cuarto del s. IV a.C. (SCHULE, Lám. 81.17 por ejemplo).

Faltan entre los materiales conservados los tipos más antiguos, como los grandes tachones repujados de bronce del tipo del hallado en la necrópolis de Puente del Obispo, o los umbos con remates radiales, que aparecen también en contextos de fines del s. V o principios del s. IV a.C. desde Aguilar de Anguita a Villaricos. Bastante chocante es el pequeño y fragmentado umbo de hierro conservado en el Museo de Córdoba (SCHULE, 1969:Lám. 81.24) pero que luego no ha sido catalogado por Vaquerizo (1989), de una tipología que pudiera ser la que habitualmente se da en el mundo meseteño, y especialmente en la zona abulense y cuenca media del Duero. Se trata de un caso único en Andalucía y casi único en todo el mundo ibérico, para el que no tenemos por ahora explicación. Sin embargo, al estar fragmentado y faltar el cierre superior del umbo, no contamos con los elementos tipológicos necesarios para definir si nos hallamos ante un tipo indudablemente meseteño (con borde dentado al interior y barras cruciformes) o un modelo más general (forma hemiesférica) no necesariamente meseteño.

Aunque no se conservan restos de petos, grebas o casos metálicos, no cabe duda de que dichos elementos, desde el s. IV a.C en adelante, estuvieron habitualmente realizados en cuero, tela u otras materias orgánicas perecederas. De hecho, la única ausencia que nos llama la atención es la de los cascos tardío sde tipo Montefortino.

\section{Arreos de caballo}

Los arreos de caballo no son exactamente armas, pero habitualmente se estudian con ellas por razones simbólicas más que funcionales. Aquí no haremos por tanto consideraciones tipológicas, que requerirían un estudio independiente, sino sólo alguna observación general. 
Se sabe, por un lado de cinco espuelas citadas por MARAVER (1867b:235), una de bronce y cuatro de hierro, que a juzgar por su descripción coinciden con el tipo habitual ibérico:

"Una espuela de bronce (carcar), y cuatro de hierro. Unas tienen redondo el semicírculo que las forma y termina en dos pequeños botones; y otras forman una chapa terminada por dos bujeros (sic) por donde pasaba la correa que las sujetaba. Todas tienen en el centro el aguijon".

Lo único notable es que habitualmente el cuerpo de la espuela es de bronce, siendo de hierro sólo el aguijón.

Choca en cambio, y hasta cierto punto, la elevada proporción de bocados de caballo que, si bien no son estrictamente armas, comparten con ellas un puesto destacado en el ethos caballeresco y guerrero característico de las sociedades ibéricas y en especial de sus grupos dominantes. Y resulta sorprendente porque dichos elementos son mucho más escasos -en números relativos y absolutos en yacimientos más grandes (Cigarralejo, Murcia), de zonas más ricas y sobre todo más aptas que la Subbética Cordobesa para el empleo del caballo (QUESADA, 1989d:332-333). En todo caso, y aunque Schule recoge estas piezas como procedentes de Almedinilla, Maraver no las cita y el libro de registro del Museo Arqueológico Nacional no es claro respecto al origen (VAQUERIZO, 1990a:229), por lo que incluso cabría la posibilidad de que estos bocados no procedan de nuestro yacimiento.

Si efectivamente son piezas de Los Collados, la solución al primer problema radicaría en que el caballo no es un arma de guerra como tal, de modo que no debemos visualizar formaciones de caballería ni en las llanuras de Albacete ni en las sierras subbéticas, sino que era un símbolo de elevado estatus social -militar, político, económico, etc.-. Su abundancia comparativa en Almedinilla puede incluso deberse a las condiciones excepcionalmente buenas de preservación de los materiales, que en el caso de los bocados formados por barras y anillas susceptibles de profunda oxidación- ha facilitado su conservación y sobre todo la posibilidad de su reconocimiento como tales arreos de montar.

\section{Algunas conclusiones}

En conjunto, las armas de Almedinilla presentan una filiación cultural claramente bastetano-contestana, sin apenas vestigios de influencia meseteña, discernible sólo en algunas puntas de lanza y quizá en un fragmento de umbo de escudo. Eso no significa que alguno de los tipos de armas (soliferrea) o de rasgos formales (antenas) no tengan un origen remoto norpirenaico, pero dichos tipos y rasgos llegaron a la Meseta y Andalucía casi simultáneamente, sin una previa elaboración meseteña con transmisión posterior. 
Almedinilla es así un perfecto ejemplo de las ricas producciones de la Alta Andalucía, comparables a las del Sureste aunque peor conocidas, ejemplo que resiste perfectamente la comparación con otros yacimientos del entorno cercano (andaluces) y lejano (Murcia) tanto en los tipos de armas, proporciones de las mismas y composición general de la panoplia, en un periodo que va del s. IV al II a.C.

Presenta un número elevado de decoraciones damasquinadas que -quizá- habría que poner en relación con Cástulo, y con seguridad con el área de Illora-Moclín. Con todo, el armamento castulonense resulta diferente al de Almedinilla y en general al de las tierras altas de Córdoba, Jaén y Granada, no tanto por las combinaciones de armas en los ajuares (no hay una muestra estadísticamente significativa), sino por la mayor variabilidad del armamento castulonense, que incluye en sus ajuares desde puntas de flecha fenicio-púnicas hasta antiguas producciones de espadas de antenas paralelizables a los tipos meseteños antiguos, presentando además una proporción menor de falcatas frente a armas de hoja recta. La lamentable pérdida de lo mejor de los conjuntos metálicos de yacimientos como Galera dificulta los análisis estadísticos, aunque seguimos trabajando en esa línea.

Entre las armas de Almedinilla encontramos algunos -escasos- restos de producciones muy antiguas, como las espadas de frontón, que en este caso son quizá sus elementos más antiguos, datables muy a principios del s. IV. Faltan, para poder remontarnos al s. V a.C. elementos tales como las grandes lanzas de base en ángulo recto, discos-coraza o tachones broncíneos repujados para escudos. Por el otro extremo, encontramos algunas lanzas que a nuestro juicio podrían datarse en el s. II, fecha que no es contradictoria con la de las falcatas -que perduran hasta épocas incluso posteriores-.

Las armas de Almedinilla forman una panoplia que, a falta de ajuares completos, permite hablar de un fuerte predominio del combate cuerpo a cuerpo basado en una lanza grande y pesada, acompañada probablemente de una falcata y quizá de una lanza más pequeña. La escasez aparente de armamento defensivo no debe engañamos: los restos de manillas de escudo, aunque pequeños y fragmentarios, nos hablan de la abundancia de este tipo de arma defensiva, que puede alcanzar gran tamaño como muestran ejemplares paralelos y mucho mejor conservados de manillas halladas en la cercana necrópolis de Los Torviscales en Fuente Tójar.

La ausencia de corazas se debe más a una cuestión cronológica -a partir del s. IV desaparecieron la coraza y grebas metálicas- que a su ausencia (casi con seguridad abundaban protecciones de tela y/o cuero). En cambio, la ausencia de cascos metálicos de tipo Montefortino, presentes aunque no frecuentes en otros yacimientos bastetanos indica, bien una cronología general anterior al s. III a.C., bien una cierta marginalidad fronteriza de Almedinilla (contrastada geográficamente pero chocante con la abundancia de damasquinados en plata), o bien simplemente la acción del azar.

Por último, cabe recordar que los cuchillos alfacatatados no pueden ser considerados como armas más que la moderna navaja multiusos "suiza". Desde un punto de vista 
funcional, no son "armas" en sentido estricto, aunque eventualmente pudieran ser usadas como tales lo mismo que una piedra o un pico. Desde un punto de vista de la consideración simbólica como objeto de prestigio, el cuchillo afalcatado de hierro parece haber gozado de consideración similar al arma durante el Periodo Orientalizante (o, en términos globales, durante la Primera Edad del Hierro), pero no a partir del siglo V a.C.

\section{Bibliografía}

AGUILERA Y GAMBOA, E. (1916) “Las necrópolis ibéricas”, Asociación Española para el progreso de las Ciencias. II. Madrid.

ALMAGRO GORBEA, M. (1982) "Tumbas de cámara y cajas funerarias ibéricas. Su interpretación socio-cultural y la delimitación del área cultural ibérica de los bastetanos", Homenaje a C. Fernández Chicarro 250-257.

BELEN, M.; ESCACENA, J.L. (1990 e.p.) “'Las comunidades prerromanas de la Baja Andalucía”. I Congreso de Paletnología de la Península Ibérica. Madrid.

BENDALA GALAN, M. (1987) “'Los cartagineses en España”, Historia General de España y América, RIALP, I.2, 115-168.

BENDALA GALAN, M. (1989) "La génesis de la estructura urbana en la España Antigua", CUPAUAM 16, 127-147.

CABRE DE MORAN, M.E. (1934a) “'El modelo de falcata más típicamente hispánico', Anuario del Cuerpo Facultativo de Archivos, Bibliotecas y Museos II, 207-213.

CABRE DE MORAN, M.E. (1934b) "Dos tipos genéricos de falcata hispánica" A.Esp. Arte y Arqueología, X, 207-225.

CABRE DE MORAN, M.E. (1990) "Espadas y puñales de las necropolis celtibericas”, Necrópolis Celtibéricas. II Simposio sobre los Celtíberos, 205-224.

CARTAILHAC, J (1886) Les Ages préhistoriques de l' Espagne et du Portugal. París.

CORREIA, V. (1925) Uma conferencia sóbre a Necropole de Alcácer do Sal. Coimbra.

CUADRADO, E. (1981) "Las necrópolis peninsulares en la Baja Epoca de la Cultura Ibérica”, La Baja Epoca de la Cultura Ibérica. 51-69.

CUADRADO, E. (1987) La necrópolis Ibérica de "El Cigarralejo" (Mula Murcia), BPH, XXIII. Madrid.

CUADRADO, E. (1989) La panoplia ibérica de 'El Cigarralejo'(Mula, Murcia). Murcia.

CHAPA BRUNET, T. (1986) Influjos griegos en la escultura zoomorfa ibérica. Iberia Graeca, 2. Madrid.

DOMINGUEZ MONEDERO, A. (1988) “'Algunas observaciones en torno al 'comercio continental griego'en la Meseta Meridional', I Congreso de Historia de Castilla-La Mancha, III.2, 327-334. 
ESCACENA, J.L. (1987) “El poblamiento ibérico en el Bajo Guadalquivir”, Iberos. Actas de las I Jornadas sobre el Mundo Ibérico. Jaén. 273-298.

ESCACENA, J.L. (1989) “'Los turdetanos o la recuperación de la identidad perdida", Tartessos. Arqueología Protohistórica del Bajo Guadalquivir. 433-476.

FULGOSIO, M. (1872) “'Armas antiguas de bronce e hierro: su estudio y comparación con las que se Conservan en el Museo Arqueológico Nacional'. Museo Español de Antigüedades, I, 353-372.

HARRISON, R.J. (1980) "A tin-plated dagger of the Early Iron Age from Spain”, Madrider Mitteilungen 21, 140-146.

MARAVER, L. (1867a) "Descubrimientos arqueológicos en Almedinilla" Revista de Bellas artes e Histórico Arqueológica Serie II, Tomo II, 9-10.

MARAVER, L. (1867b) “'Expedición arqueológica a Almedinilla”, Rev. de Bellas Artes e Histórico Arqueológica Serie II, tomo II, 307-328.

NIETO GALLO, G.; ESCALERA UREÑA, A. (1970) “Estudio y tratamiento de una falcata de Almedinilla", Informes y trabajos del ICROA 10, 5-31.

PARIS, P. (1904) Essai sur l' art et l' industrie de l' Espagne primitive. París.

PASTOR, M.; CARRASCO, J.; PACHON, J.A. (1990 e.p.) "Paleoetnología de Andalucía Oriental (Etnogeografía)", I Congreso de Paletnología de la Península Ibérica. Madrid.

PEREIRA SIESO, J. (1988) La cerámica pintada a torno en Andalucía entre los siglos VI y III a.C. en la cuenca del Guadalquivir Tesis Doctorales Universidad Complutense de Madrid.

PEREIRA SIESO, J. (1989) "Necropolis ibéricas andaluzas. Nuevas perspectivas en su valoración y estudio'”. Tartessos. Arqueología protohistórica del Bajo Guadalquivir. 477-494.

QUESADA SANZ, F. (1988) "Las acanaladuras en las hojas de falcatas ibéricas”, CUPAUAM 15, 275-299.

QUESADA SANZ, F. (1989a) "La utilización del arco y las flechas en la Cultura Ibérica”, Trabajos de Prehistoria 46, 161-201.

QUESADA SANZ, F. (1989b) “'Consideraciones sobre el uso del armamento ibérico para la delimitación de unidades geopolíticas', Fronteras. Arqueología Espacial 13, 111-120.

QUESADA SANZ, F. (1989c) Armamento, guerra y sociedad en la necrópolis ibérica de 'El Cabecico del Tesoro'(Murcia, España) BAR IS 502, 2 vols.

QUESADA SANZ,F. (1989d) Recensión de W. Kurtz, La Necrópolis de las Cogotas. En Archivo Español de Arqueología 62, 330-334.

QUESADA SANZ, F. (1990a) "La falcata ibérica: ¿un arma de origen ilirio y procedencia itálica?", Archivo Español de Arqueología 63, 65-93.

QUESADA SANZ, F. (1990b) "Falcatas ibéricas con damasquinados en plata", Homenaje a D. Emeterio Cuadrado díaz. Verdolay. 2, 45-59. 
QUESADA SANZ, F. (1990c) “Armamento de supuesta procedencia meseteña en las necrópolis ibéricas de Murcia”, Necrópolis Celtibéricas. II Simposio sobre los celtíberos. pp. 231-240.

QUESADA SANZ, F. (1991) El Armamento Ibérico. Tesis Doctoral inédita. Universidad Autónoma de Madrid.

QUESADA SANZ, F. (e.p.) Arma y símbolo. La falcata ibérica. Alicante.

QUESADA SANZ, F.; VAQUERIZO GIL, D. (1990) "'Un proyecto de investigación arqueológica en Córdoba: Protohistoria y Romanización en la Subbética Cordobesa”, Anales de Arqueología Cordobesa, 1, 7-51.

QUESADA, F.; VAQUERIZO, D.; MURILLO, J.F. (1992 e.p.) “La cerámica ibérica del 'Cerro de la Cruz'. Departamentos O,P,N". Anales de Arqueología cordobesa. 3.

RUANO RUIZ, M.E. (1983) "Panorama de la escultura ibérica en Andalucía”, BAEAA 17, 54-68.

RUBIO DE LA SERNA, J. (1888) "Noticia de una necropolis anterromana descubierta en Cabrera de Mataro', Memorias de la Real Academia de la Historia. XI, Cuademo Complementario. Madrid.

SANDARS, H. (1913) "The Wapons of the Iberians", Archaeologia, XXV. Oxford.

SCHULE, W. (1969) Die Meseta-Kulturen der Iberischen Halbinsel. 2 vols. Berlín.

STARY, P.F. (1982) “Keltische Waffen auf der Iberischen Halbinsel” Madrider Mitteilungen 23, 114-144.

VAQUERIZO GIL, D. (1988) Aproximación al fenómeno de la Cultura Ibérica en el Sureste de la actual Provincia de Córdoba: el yacimiento del Cerro de la Cruz (Almedinilla). Universidad de Córdoba, Publicación en Microficha, 6. Córdoba.

VAQUERIZO GIL, D. (1989) “'Armas de hierro procedentes de la necrópolis ibérica de 'Los Collados' (Almedinilla, Córdoba)”, Saguntum 22, 225-266.

VAQUERIZO GIL, D. (1990a) "Armas de hierro de raigambre meseteña, en la necrópolis de Los Collados (Almedinilla, Córdoba)', Necrópolis Celtibéricas. II Simposio sobre los celtíberos. Zaragoza, 225-229.

VAQUERIZO GIL, D. (1990b) El yacimiento ibérico del Cerro de la Cruz (Almedinilla, Córdoba). Córdoba.

VICENT, A.M. (1984-85) “'Trabajos arqueológicos inéditos en Fuente Tójar (Córdoba) de L. Maraver en 1867' Corduba Archaelogica 15, 31-55. 


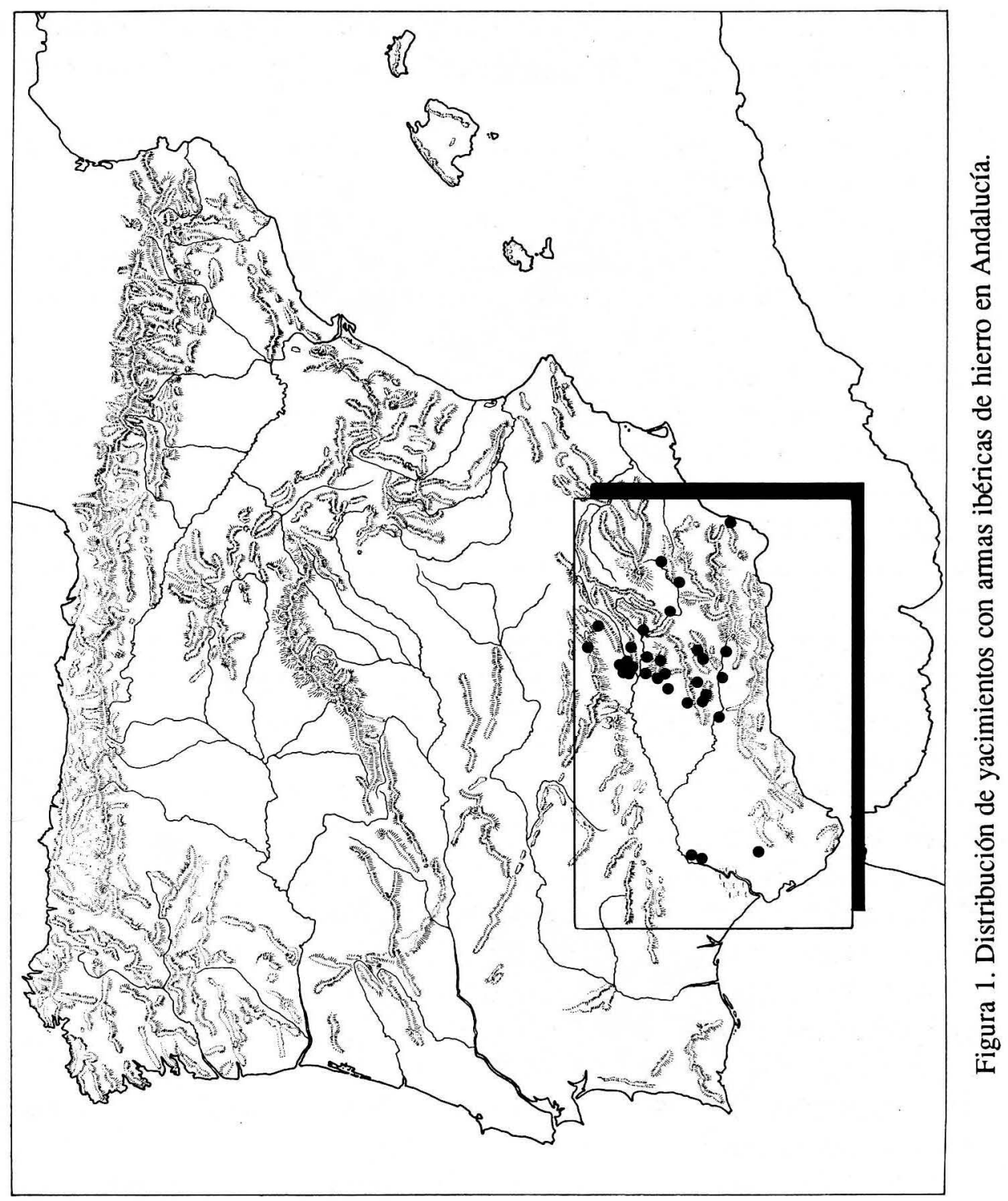



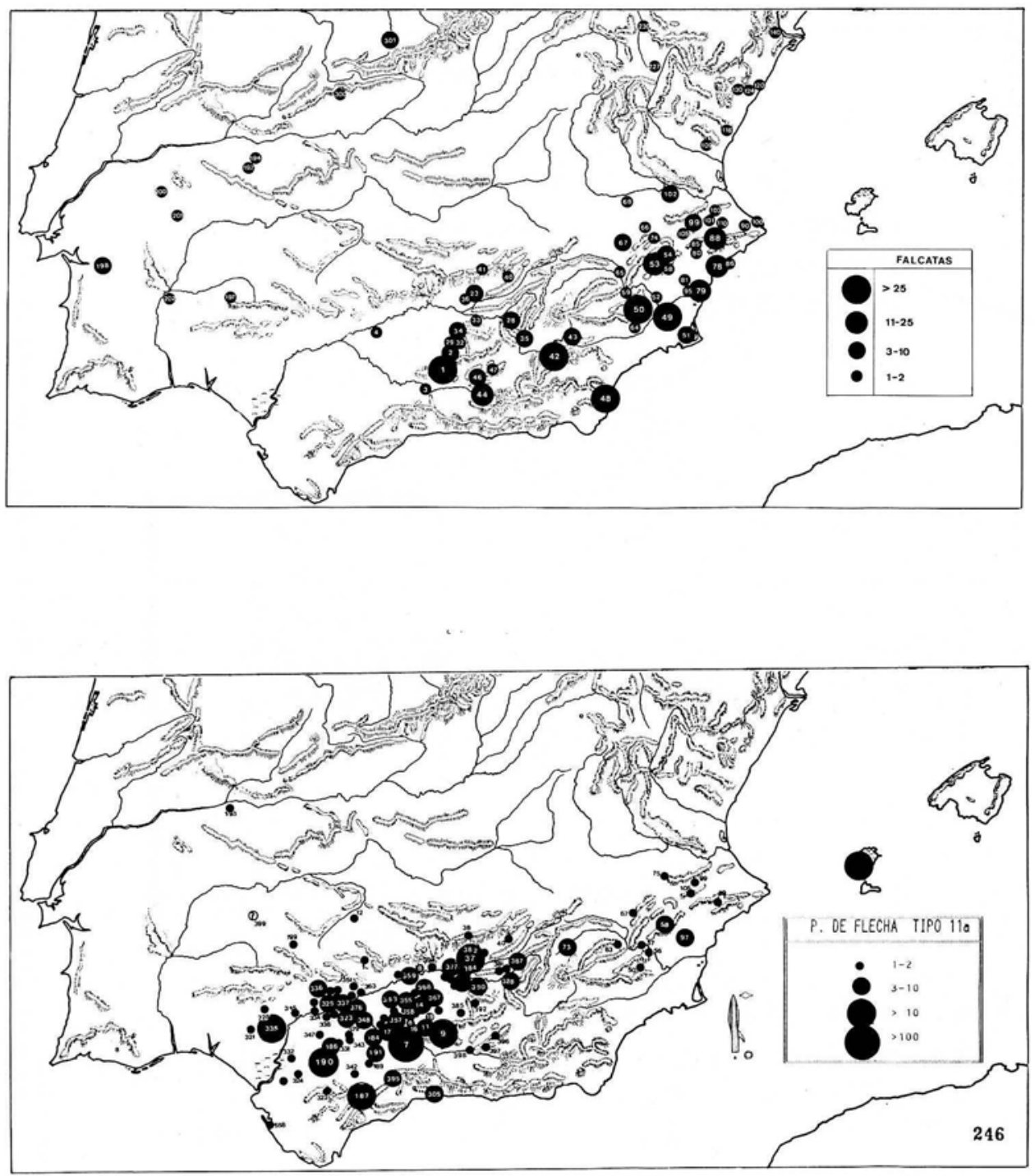

Figura 2. Distribución de falcatas ibéricas y de puntas de flecha de doble filo y anzuelo lateral. 


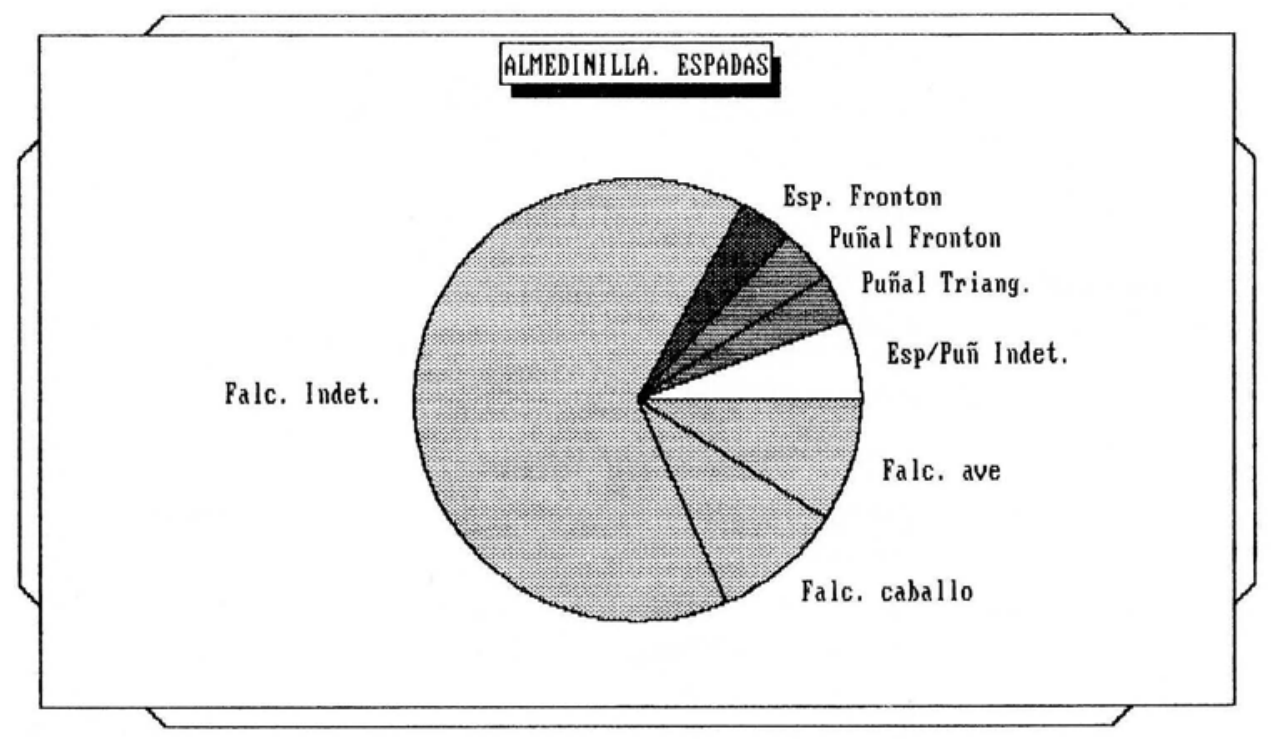

Figura 3. Distribución porcentual de los diversos tipos de espadas y puñales documentados en Almedinilla.

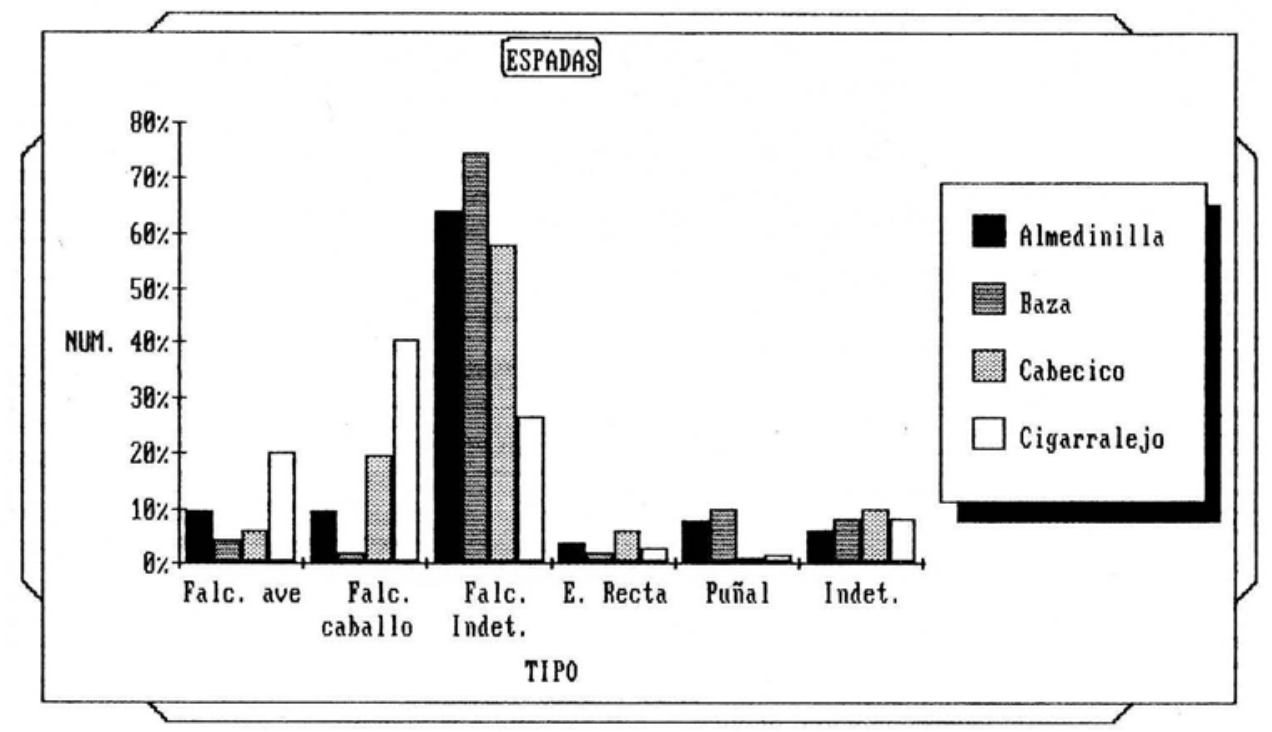

Figura 4. Comparación del conjunto de espadas de Almedinilla con los de otras grandes necrópolis ibéricas. 


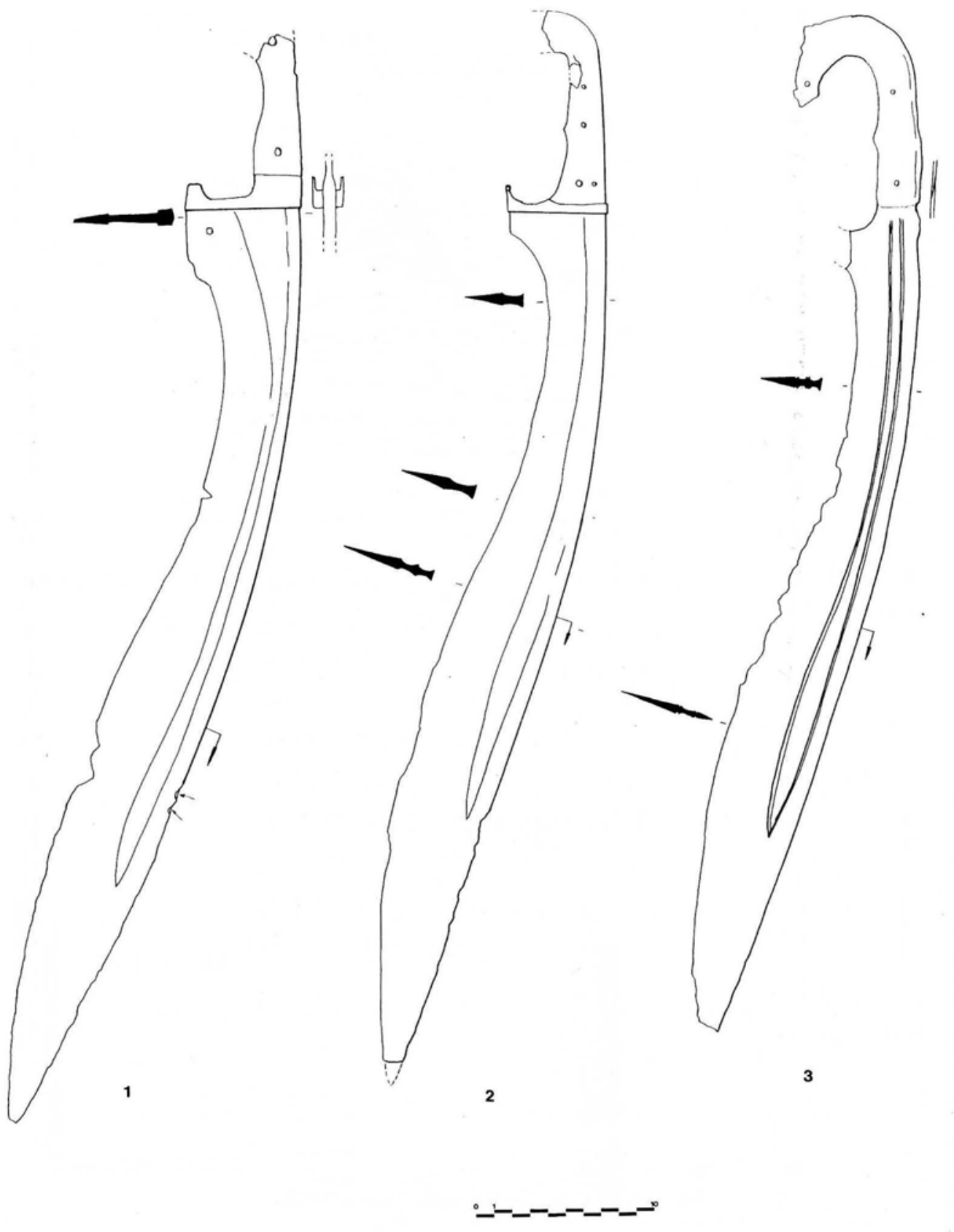

Figura 5. Falcatas de Almedinilla conservadas en el British Museum 1.-WG 1955; 2.-WG 2427; 3.-WG 1954. 


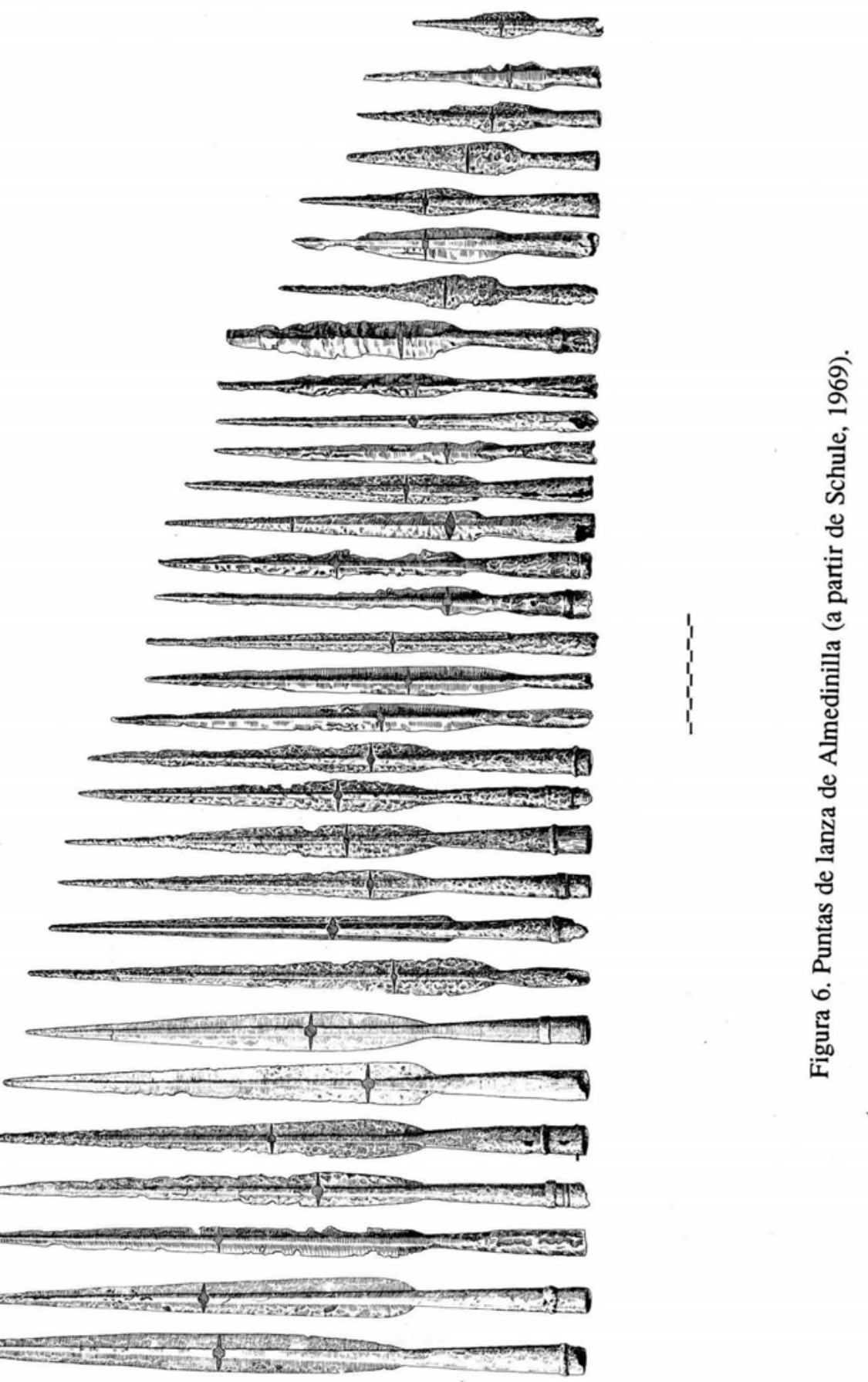

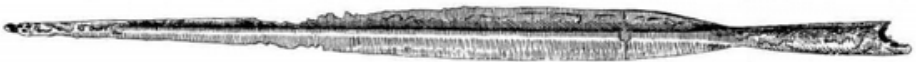

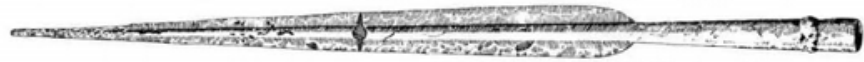

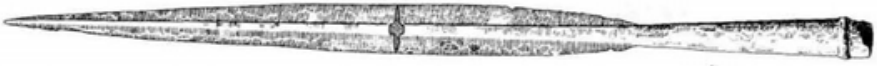

--- Grupo de investigación P.A.I. HUM 236 | http://www.arqueocordoba.com/publ/anales.htm --- 